\title{
Insulin-like growth factor-1 induces epithelial-mesenchymal transition in hepatocellular carcinoma by activating survivin
}

\author{
FANGFENG LIU, YONGJIE SUN, BINGQI LIU, JUN LU, HONGGUANG LI, HUAQIANG ZHU, \\ HENGJUN GAO, XU ZHOU and HONG CHANG
}

Department of Hepatobiliary Surgery, Shandong Provincial Hospital Affiliated

to Shandong University, Jinan, Shandong 250021, P.R. China

Received December 21, 2017; Accepted May 31, 2018

DOI: 10.3892/or.2018.6516

\begin{abstract}
Insulin-like growth factor-1 (IGF-1), a small polypeptide hormone similar to insulin in protein structures, has been identified as an activator of epithelial-mesenchymal transition (EMT) pathways in several types of cancers. As a member of the inhibitor of apoptosis protein (IAP) family, survivin is implicated in the EMT of some cancers. However, the role of survivin on IGF-1-mediated EMT of hepatocellular carcinoma (HCC) has not been clarified. In the present study, we demonstrated that survivin was involved in the EMT process induced by IGF-1 in HCC cell line SMMC7721. With administration of different concentrations of IGF-1, survivin mRNA and protein expression were significantly increased and stimulated EMT in the tested cell line, while the increased invasive and migratory abilities of HCC cells and activation of the EMT process induced by IGF-1 were reversed after silencing of survivin expression by transfecting small interfering RNA. This was further confirmed by the observation of morphological changes, the decrease of invasive and migratory abilities and the downregulation of EMT markers, N-cadherin, vimentin and Snail, and the upregulation of E-cadherin. In conclusion, survivin may play a vital role in the IGF-1 signaling pathway by mediating EMT in HCC through the upregulation of the expression of EMT markers, and the knockdown of survivin expression may suppress the metastasis of $\mathrm{HCC}$, which may provide new insights for the molecular therapy of HCC patients in clinical treatment.
\end{abstract}

\section{Introduction}

Liver cancer is the fifth most common cancer in men and the seventh in women. Hepatocellular carcinoma (HCC), which

Correspondence to: Professor Hong Chang, Department of Hepatobiliary Surgery, Shandong Provincial Hospital Affiliated to Shandong University, 9677 Jingshi Road, Jinan, Shandong 250021, P.R. China

E-mail: changhongdoctor@163.com

Key words: insulin-like growth factor 1, epithelial-mesenchymal transition, survivin, hepatocellular carcinoma accounts for $>85 \%$ of primary liver cancers, has a poor prognosis with 5 -year overall survival rates of $<12 \%(1,2)$. Since its poor prognosis has been reported to be closely associated with HCC recurrence and metastasis, it is essential to determine the possible underlying mechanisms which mediate tumor invasion and metastasis. EMT has been demonstrated to be involved in the progression of various cancers, including liver, prostate and breast cancer (3-5), and functions as a main step toward tumor metastasis. To date, increasing studies have been directed at uncovering the possible signaling pathways in EMT of HCC.

IGF-1 has been demonstrated to be upregulated in many different tumor cell lines compared with normal cells and involved in tumorigenesis and progression, which is mediated through the activation of multiple signal transduction pathways, including the JNK, MAPK, PI3K/Akt pathways (6). IGF-1 was found to elevate the expression of transmembrane glycoprotein MUC1 in MCF-7 cells for the initiation of EMT in a PI3K/Akt signaling pathway-dependent manner (7). Furthermore, it was reported that IGF-1 could promote the growth and metastasis of HCC cell lines via the upregulation of cathepsin B expression (8). As a member of the inhibitor of apoptosis protein (IAP) family, survivin is overexpressed in some tumor specimens, including $\mathrm{HCC}$, while it is nearly negative in normal tissue (9). In human sacral chondrosarcoma, SDF-1/CXCR4 signaling could upregulate the expression of survivin via the MEK/ERK and PI3K/AKT pathways, leading to cell cycle and EMT occurrence (10). Overexpression of survivin in HCC cells was revealed to suppress the ability of migration via upregulation of glucoseregulated protein 78 (GRP78) and reduce the EMT marker, vimentin (11). Previous studies have revealed that high levels of survivin exhibited anti-apoptotic and pro-metastatic potential in cancer cell lines but not in normal cells (12).

Although both IGF-1 and survivin could mediate metastasis in cancer cells, the mechanisms by which they co-regulate metastasis have not been uncovered. In the present study, we used various molecular and cellular methods to investigate the existence and significance of the relationship between the IGF-1 and survivin proteins. Our data elicited a new mechanism in which IGF-1 induced EMT through regulation of survivin and a downstream pathway, and this can be targeted to treat HCC patients. 


\section{Materials and methods}

Antibodies and reagents. Monoclonal rabbit antibodies against survivin (1:5,000; cat. no. 2808), Akt (1:2,000; cat. no. 2920), p-Akt (1:5,000; cat. no. 96115$)$, Snail (1:500; cat. no. 3879), vimentin $(1: 1,000$; cat. no. 5741), E-cadherin (1:1,000; cat. no. 14472), N-cadherin (1:1,000; cat. no. 13116) and GAPDH (1:5,000; cat. no. 5174) were obtained from Cell Signaling Technology, Inc. (Danvers, MA, USA). IGF-1 was purchased from Sigma-Aldrich; Merck KGaA (Darmstadt, Germany). DAPI was purchased from Invitrogen; Thermo Fisher Scientific, Inc. (Carlsbad, CA, USA).

Cell culture. Human HCC SMMC7721 cells were cultured in RPMI-1640 medium (Hyclone Laboratories; GE Healthcare, Chicago, IL, USA) supplemented with $10 \%$ fetal bovine serum (FBS; Gibco; Thermo Fisher Scientific, Inc., Waltham, MA, USA), $100 \mathrm{U} / \mathrm{ml}$ penicillin and $100 \mu \mathrm{g} / \mathrm{ml}$ streptomycin at $37^{\circ} \mathrm{C}$ with $5 \% \mathrm{CO}_{2}$.

Transfection of survivin siRNA. SMMC7721 cells were seeded in a 6-well plate and adjusted to a density of $5 \times 10^{5}$ cells/well and incubated at $37^{\circ} \mathrm{C}$ in a $\mathrm{CO}_{2}$ incubator until the cells reached $60-80 \%$ confluence. Survivin siRNA or control siRNA was provided by Shanghai GenePharma Co., Ltd., (Shanghai, China). The survivin or control siRNAs were subjected to Opti-MEM with Lipofectamine 2000 (Invitrogen) for transfection. Following a 6-h incubation, the medium was replaced with fresh DMEM (10\% FBS) and cells were collected for further experiments after $72 \mathrm{~h}$ of culture.

Wound healing assay. HCC cell migration was examined by a wound-healing assay. SMMC7721 cells were cultured to a confluent monolayer in a 6-well plate. A scratch (wound) was introduced in the confluent cell layer using a pipette tip. The cells were washed three times with PBS to remove detached cells. The cells were then incubated with different doses of IGF-1 for $24 \mathrm{~h}$, and images of a defined wound spot were captured with a phase-contrast microscope (Olympus Corp., Tokyo, Japan) at 0 and $24 \mathrm{~h}$. The width of the wound was assessed using ImageJ software (National Institutes of Health, Bethesda, MD, USA). The distance of the wound was calculated as: Distance of the wound $=$ distance at $0 \mathrm{~h}$ - distance at $24 \mathrm{~h}$.

Transwell filter cell migration and invasion assays. Boyden chambers containing polycarbonate filters with $8-\mu \mathrm{m}$ pore size (Costar Group, Bodenheim, Germany) were employed. Cells were seeded at a density of $5 \times 10^{5}$ cells $/ \mathrm{ml}$. To initiate the migration assay, cells $\left(5 \times 10^{4}\right)$ in $10 \mu 1$ of DMEM without FBS were added to the upper chamber, and the lower chamber was filled with $600 \mu \mathrm{l}$ of DMEM with $10 \%$ fetal calf serum (FCS). For the invasion assay, Matrigel was introduced in DMEM (4:3) in the inner chamber. IGF-1 was used as an inducer of cell migration and the cells were allowed to migrate for $12 \mathrm{~h}$ at $37^{\circ} \mathrm{C}$. Cells on the filter were first stained with crystal violet, and the cells that remained on the upper surface of the filter were removed using a cotton swab. The cells that had migrated onto the lower surface of the filter were examined using a microscope (Olympus Corp.) after mounting them onto a slide. A total of six random fields (magnification, x100) per filter were photographed. Experiments were carried out in triplicate with consistent results.

RNA extraction and quantitative real-time PCR. RNA extraction was prepared using TRIzol reagent (Takara Biotechnology Co., Ltd., Dalian, China) according to the manufacturer's instructions. Total RNA $(1 \mu \mathrm{g})$ was used to synthesize the first strand of cDNA using BestarqPCR RT kit (DBIBioscience, Ludwigshafen, Germany). The mRNA expression was evaluated by real-time qPCR on the Stratagene Mx3000P real- time PCR platform (Agilent Technologies, Santa Clara, CA, USA) with SYBRGreen PCR core reagents. The PCR reaction system contained $10 \mu \mathrm{l}$ of Bestar $^{\circledR}$ SYBR Green qPCR Master Mix, $1.0 \mu \mathrm{l}$ of forward and reverse primers $(10 \mu \mathrm{M}), 1 \mu \mathrm{l}$ of cDNA template, and $8 \mu \mathrm{l}$ of $\mathrm{ddH}_{2} \mathrm{O}$. GAPDH was applied as a reference. The following primers were synthesized and applied: survivin forward, 5'-TCAAGGACCACCGCATCT-3' and reverse, 5'-CGCACTTTCTCCGCAGTT-3'; Snail forward, 5'-TCC TTCGTCCTTCTCCTCTAC-3' and reverse, 5'-TGTGGCTTC GGATGTGC-3'; E-cadherin forward, 5'-CCGATCTTCAAT CCCACC-3' and reverse, 5'-CCCACGCCAAAGTCCTC-3'; vimentin forward, 5'-CGCCAGATGCGTGAAAT-3' and reverse, 5'-CACGAAGGTGACGAGCC-3'; N-cadherin forward, 5'-GGA TCAAAGCCTGGAACAT-3' and reverse, 5'-CTTGGAGCC TGAGACACGA-3'; GAPDH forward, 5'-TGTTCGTCATGG GTGTGAAC-3' and reverse, 5'-TGTTCGTCATGGGTGTG AAC-3'. The reaction procedure was initiated with denaturation at $94^{\circ} \mathrm{C}$ for $2 \mathrm{~min}$ and followed by 40 repeated cycles (denaturation at $94^{\circ} \mathrm{C}$ for $20 \mathrm{sec}$, annealing at $58^{\circ} \mathrm{C}$ for $20 \mathrm{sec}$ and extension at $72^{\circ} \mathrm{C}$ for $20 \mathrm{sec}$ ). The $\mathrm{Ct}$-value for each sample was calculated with the $\Delta \Delta \mathrm{Cq}$-method, and the results were expressed as $2^{-\Delta \Delta \mathrm{Cq}}$ to analyze the fold change (13).

Western blotting. HCC cells were lysed with lysis buffer containing $135 \mathrm{mM} \mathrm{NaCl}, 20 \mathrm{mM}$ Tris ( $\mathrm{pH} 7.5), 25 \mathrm{mM}$ $\beta$-glycerophoshate, $2 \mathrm{mM}$ EDTA, $2 \mathrm{mM}$ sodium pyrophosphate, 2 mM DTT, $10 \%$ glycerol, $1 \%$ Triton X-100, $10 \mathrm{mM}$ $\mathrm{NaF}, 1 \mathrm{mM}$ sodium orthovanadate and $1 \mathrm{mM}$ PMSF supplemented with a complete protease inhibitor cocktail (Roche Diagnostics $\mathrm{GmbH}$, Mannheim, Germany) at $4^{\circ} \mathrm{C}$. Lysates were centrifuged $(15,000 \mathrm{xg})$ at $4^{\circ} \mathrm{C}$ for $15 \mathrm{~min}$. Equal amounts of the soluble protein were denatured in SDS, resolved on $12 \%$ SDS-polyacrylamide gel, and transferred onto polyvinylidene fluoride (PVDF) membranes (EMD Millipore, Bedford, MA, USA), and incubated with blocking buffer (5\% non-fat dry milk in TBST) overnight at $4^{\circ} \mathrm{C}$. Immunoblotting was performed with a primary antibody $(1: 1,000)$ followed by the appropriate horseradish peroxidase (HRP)-conjugated goat anti-rabbit antibody (1:15,000; Cell Signaling Technology, Inc., Danvers, MA, USA). Immunodetection was performed with an enhanced chemiluminescence system (ECL; Pierce Biotechnology, Rockford, IL, USA) using hydrogen peroxide and luminol as a substrate.

Immunofluorescence staining. Briefly, after experimental treatment, SMMC7721 cells were incubated with a primary antibody at $4^{\circ} \mathrm{C}$ overnight. After being washed three times with PBS, the cells were incubated with Alexa Fluor 488-labeled secondary goat anti-rabbit antibody (1:10,000; cat. no. 4412; Cell Signaling Technology, Inc.) for $1 \mathrm{~h}$ at $37^{\circ} \mathrm{C}$. The cells were then stained 
A

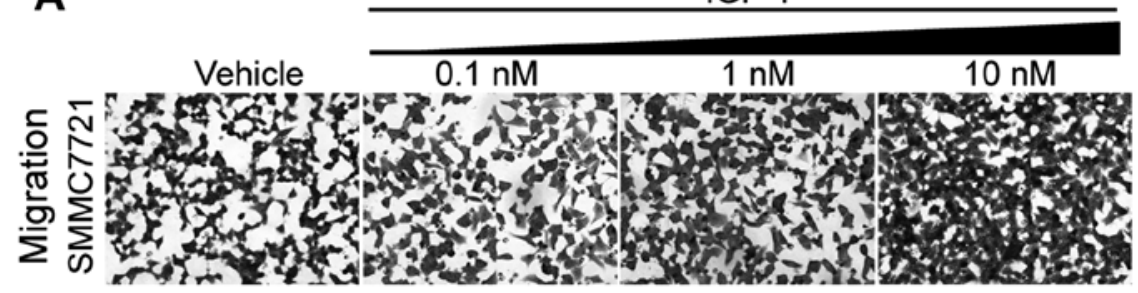

B

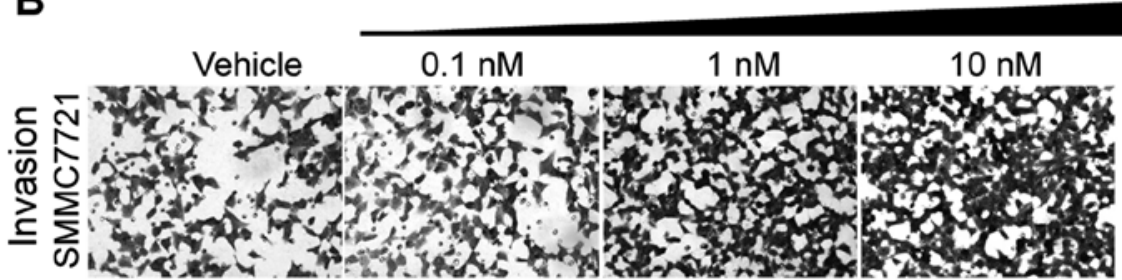

IGF-1

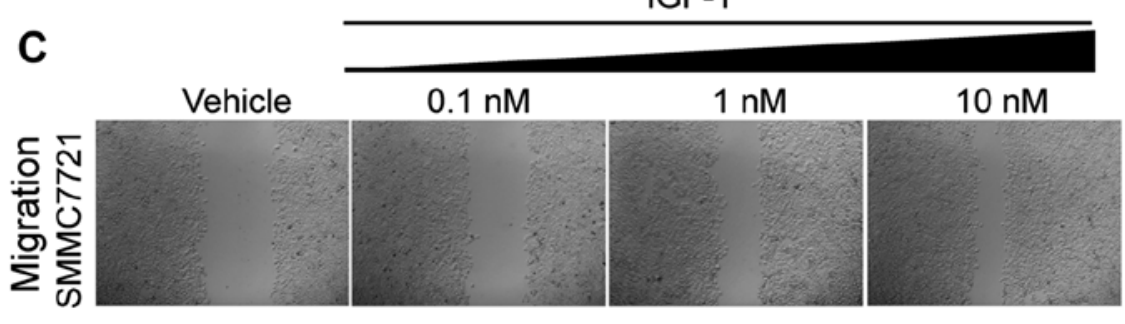

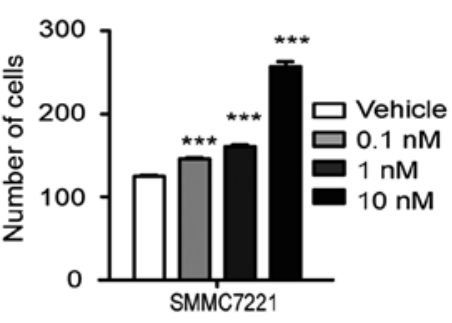
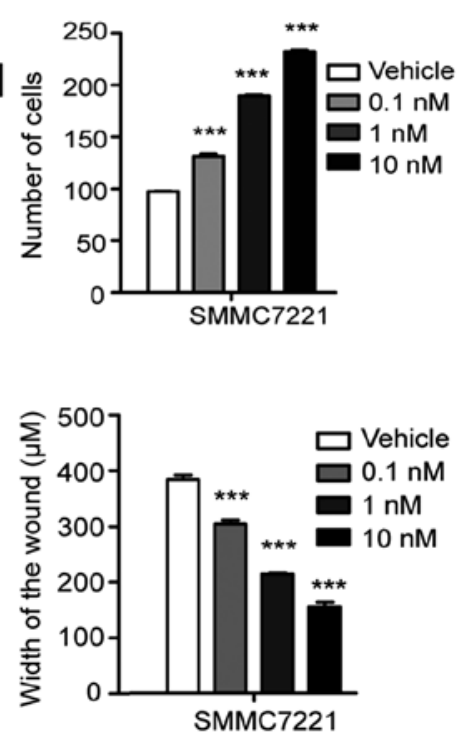

Figure 1. IGF-1 enhances the invasive and migratory abilities of HCC cells. (A) The impact of IGF-1 on migratory ability in a Transwell filter assay. (B) The impact of IGF-1 on invasive ability in a Transwell filter assay. (C) The impact of IGF-1 on migration ability in a wound healing assay. ${ }^{* * *} \mathrm{P}<0.001$ compared to the control. IGF-1, insulin-like growth factor-1.

with DAPI to visualize cell nuclei and observed under a confocal microscope (Nikon A1+; Nikon Corp., Tokyo, Japan).

Statistical analysis. GraphPad Prism version 5.0 (GraphPad Software, Inc., La Jolla, CA, USA) was used to analyze the experimental data, all the results were presented as the mean \pm standard deviation (SD) from three independent experiments. The statistical analysis was performed using one-way analysis of variance (ANOVA), followed by Dunnett's t-test. $\mathrm{P}<0.05$ was considered to indicate a statistically significant difference.

\section{Results}

IGF-1 enhances the invasive and migratory abilities of $\mathrm{HCC}$ cells. To determine the effect of IGF-1 on the invasive and migratory abilities of HCC cells, different concentrations of IGF-1, including $0.1,1$ and $10 \mathrm{nM}$, were added to perform the wound healing assay and Transwell filter cell migration and invasion assays (Fig. 1). Statistical analysis revealed that in both the invasive and migratory assays the number of cells were significantly increased with the increasing doses of IGF-1, in comparison with the vehicle group (Fig. 1A and B). In addition, the distance of the wound healing was markedly decreased in the IGF-1treatment groups in a dose-dependent manner (Fig. 1C). These results demonstrated that cellular invasive and migratory abilities were highly promoted by IGF-1, indicating that IGF-1 may act as an epigenetic activator of invasion and migration of HCC cells.
IGF-1 activates EMT in HCC cells. Losing cohesive ability and epithelial phenotype and acquiring spindle or fiber-like shapes are classic morphological changes in the process of EMT $(14,15)$. Similar morphological changes as in EMT were observed in HCC cells after treatment with IGF-1 (Fig. 2A), hence it was speculated that IGF-1 enhances the invasive and migratory potential via activation of the EMT-related pathway. To confirm this hypothesis, we compared the mRNA and protein expression patterns of EMT-associated genes of IGF-1-treated cells to that of control cells at different concentrations. As shown in Fig. 2B and C, the expression levels of vimentin, Snail and $\mathrm{N}$-cadherin were notably increased while E-cadherin was significantly decreased at both transcription levels and protein levels in a dose-dependent manner, indicating that EMT was activated in SMMC7221 cells after treatment with IGF-1.

Effect of IGF-1 on survivin expression. It was reported that survivin could be mediated by IGF-1/mTOR signaling (4) and that survivin participated in the activation of EMT in colon cancer cells (16). It could be speculated from these facts that IGF-1 may activate EMT by mediating survivin expression. Thus, we assessed the ability of IGF-1 to affect the expression level of survivin using RT-qPCR, western blot analysis and immunofluorescence staining. With the increase in the concentration of IGF-1 from 0.1 to $10 \mathrm{nM}$, the expression pattern of survivin significantly increased at both the mRNA and protein levels $(\mathrm{P}<0.01, \mathrm{P}<0,001)$ (Fig. 3A and B). A similar tendency was observed in the immunofluorescence staining 


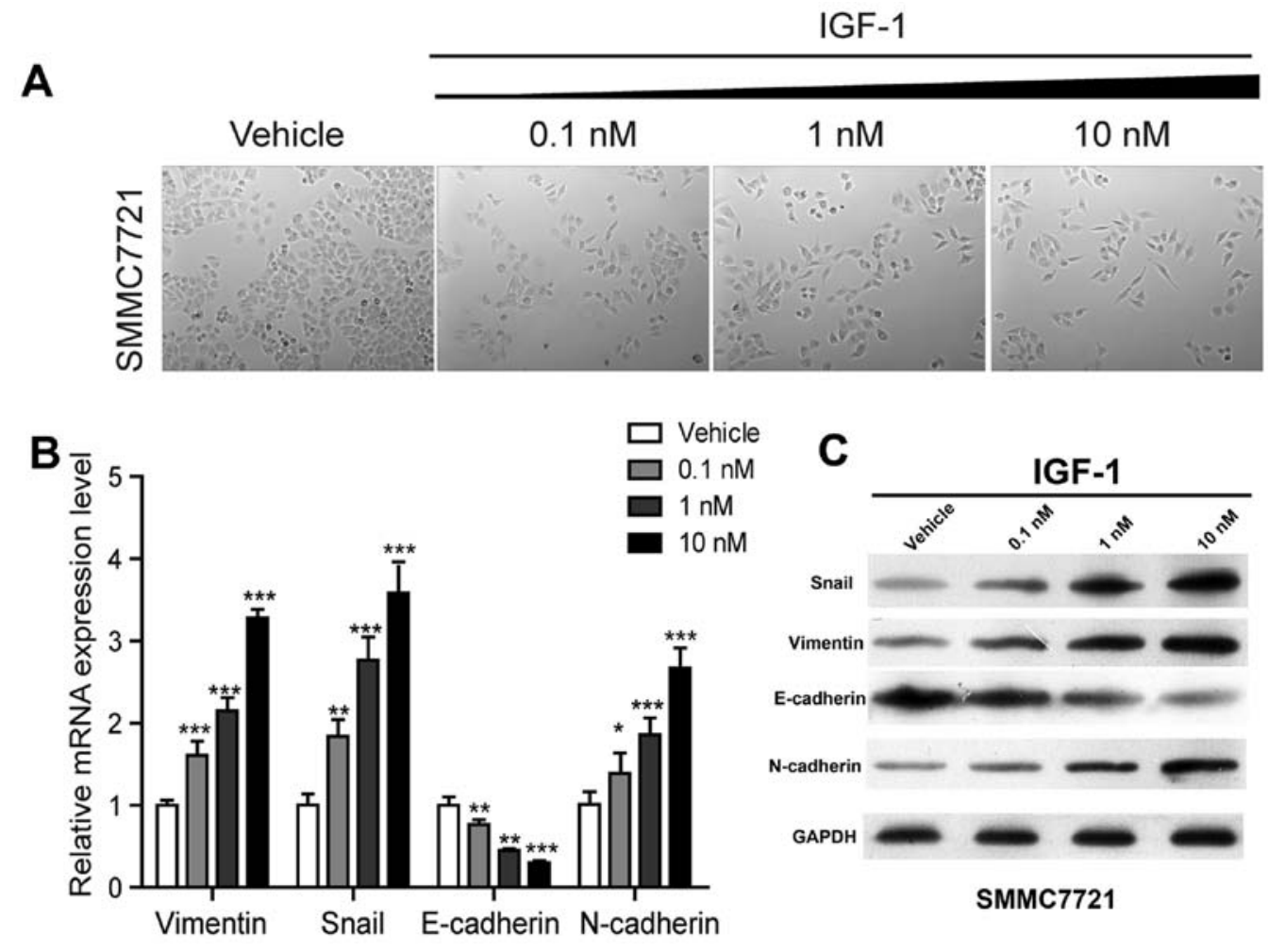

Figure 2. IGF-1 induces EMT by modulating the expression of EMT-associated genes. (A) Morphological change of HCC cells after treatment with IGF-1. (B) Relative mRNA expression of EMT-associated genes using RT-PCR after IGF-1 treatment. (C) Relative protein expression of EMT-associated genes using western blotting after IGF-1 treatment. $\mathrm{P}<0.05,{ }^{* *} \mathrm{P}<0.01$ and ${ }^{* * * *} \mathrm{P}<0.001$ compared to the control. IGF-1, insulin-like growth factor-1; EMT, epithelial-mesenchymal transition.

A

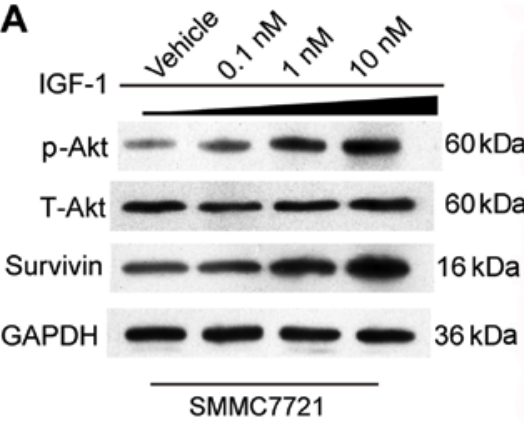

B

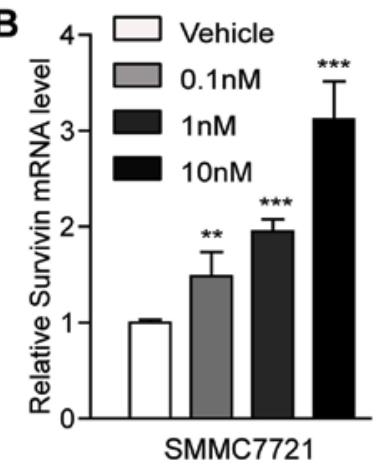

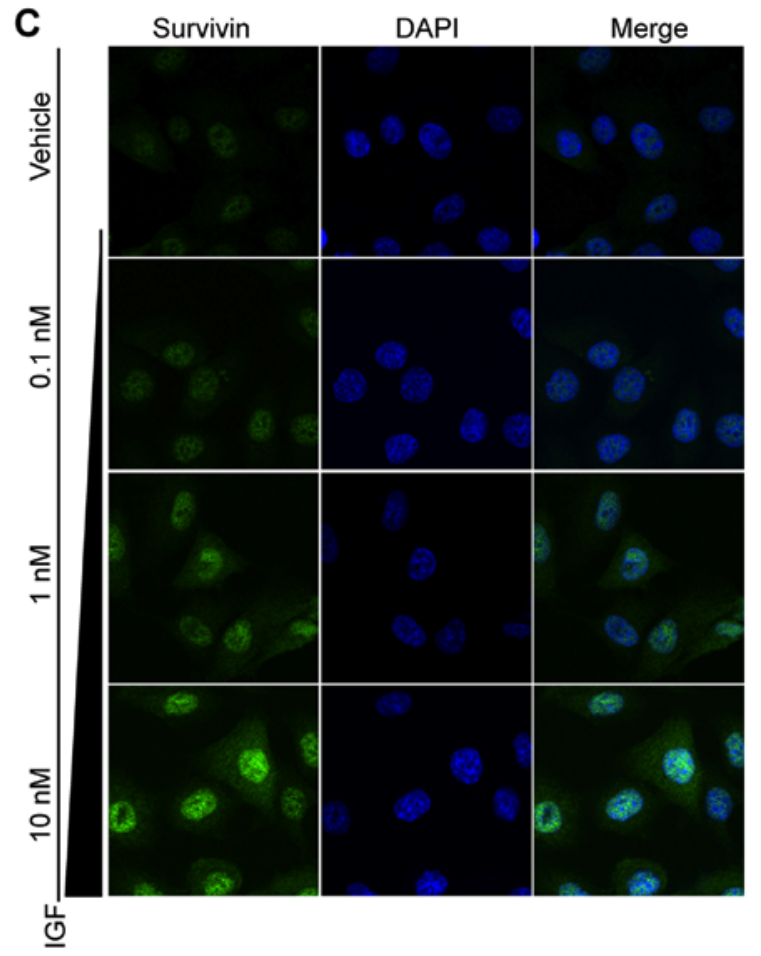

Figure 3. The expression patterns of survivin in HCC treatment with different concentrations of IGF-1. The expression of survivin was assessed using (A) western blot analysis and (B) RT-PCR. (C) Immunofluorescence staining for survivin in HCC treatment with different concentrations of IGF-1. ${ }^{* *} \mathrm{P}<0.01$ and ${ }^{* * *} \mathrm{P}<0.001$ compared to the control. IGF-1, insulin-like growth factor-1; HCC, hepatocellular carcinoma.

results (Fig. 3C). These results implied that survivin may be involved in the IGF-1-induced EMT process.
In addition, it is well-known that IGF-1 participates in the activation of different signal transduction pathways, including 
A

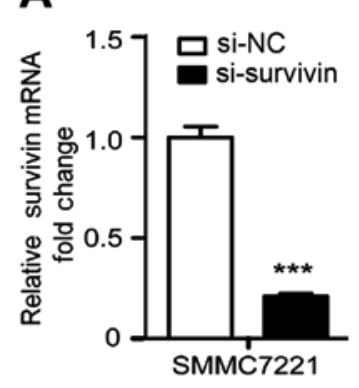

B

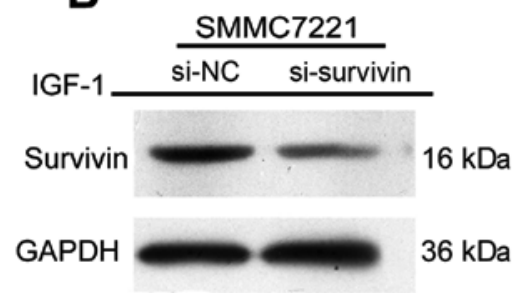

C

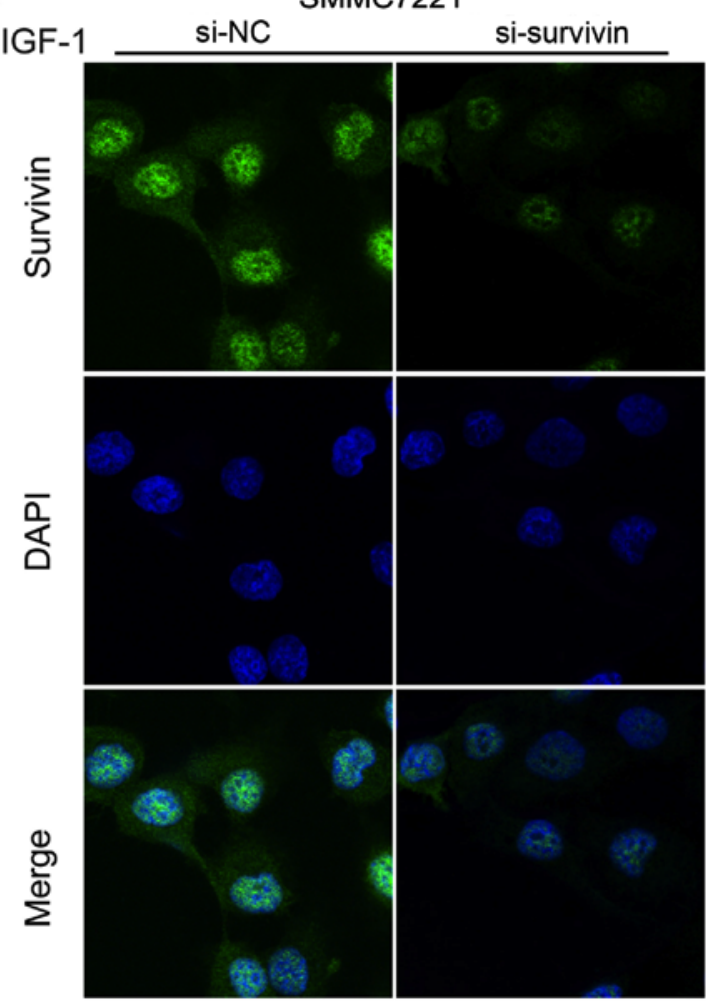

Figure 4. The effect of survivin on the EMT process. (A) Knockdown proficiency of survivin in HCC assessed by RT-PCR. ${ }^{* * *} \mathrm{P}<0.001 \mathrm{compared}$ to the control. (B) Knockdown proficiency of survivin in HCC assessed by immunofluorescence staining. (C) Morphological change of HCC cells after silencing of survivin and treatment with IGF-1. HCC, hepatocellular carcinoma; IGF-1, insulin-like growth factor-1.

the PI3K/AKT/mTOR pathway $(17,18)$. In the present study, our western blot results also revealed that AKT was activated and the p-AKT expression levels were significantly elevated in the IGF-1-treated groups in comparison with the vehicle group $(\mathrm{P}<0.05)$ (Fig. 3A).

Survivin knockdown eradicates IGF-1-induced EMT in HCC cells. To further confirm the effect of survivin on the IGF-1induced EMT process, survivin siRNA was transfected to silence survivin expression promoted by IGF-1 at a concentration of $10 \mathrm{nM}$ and the results revealed that survivin expression at the mRNA and protein levels were significantly reduced $(\mathrm{P}<0.001)$ (Fig. 4). After silencing survivin expression in HCC cell lines, there was a significant decrease in cell invasion and migration $(\mathrm{P}<0.001)$ (Fig. 5E and F). Furthermore, EMT events were evaluated by observing cell morphological changes and assessed the expression levels of EMT markers in mRNA and protein. As shown in Fig. 5A-D, there was a changeover in EMT marker expression and cell phenotype in the survivinsiRNA cells compared with the control-siRNA cells. These results indicated that silencing of survivin recovered the EMT process of HCC induced by IGF-1.

\section{Discussion}

EMT is a reversible process in which epithelial cells lose their cell polarity and cell-cell adhesion and acquire mesenchymal features. During carcinogenesis, EMT enables tumor cells to become invasive via downregulation of epithelialspecific markers including E-cadherin, thyroid transcription factor-1 (TTF-1) and ZEB and upregulation of mesenchymal markers including vimentin, $\alpha$-SMA, N-cadherin and transcription factor Snail (19-26). EMT is found to be a major event in tumor metastasis by changing the cohesive ability of cells and enhancing the invasive and migratory potential (27) and different biomarkers mediating the EMT process have been identified. In addition, various tumor-associated growth factors have been identified to be involved into EMT, such as VEGF, EGF and TGF- $\beta$ (28).

The important effect and involvement of IGF-1 in metastasis have been well elucidated. IGF-1 affects cell invasion by suppression of PTEN phosphorylation and interaction with the PI3K/PTEN/Akt/NF-KB signaling pathway in pancreatic cancer (29). In addition, IGF-1, together with latent TGF- $\beta$ can activate metalloproteinase activity (MMP) and then result in EMT in MCF-7 breast cancer cells (30). IGF-1 was found to elevate the expression of transmembrane glycoprotein MUC1 in MCF-7 cells for the initiation of EMT in a PI3K/Akt signaling pathway-dependent manner (7). IGF-1 was also reported to activate $\mathrm{PI} 3 \mathrm{~K} / \mathrm{AKT} / \mathrm{mTOR}$ signaling to increase the expression of survivin and control the expression of EMT biomarkers in the development of gastric, prostate and colon cancer cells $(4,16,31)$. However, the relationship between IGF-1 and survivin in HCC was unclear. In the present study, we also found that AKT was activated with the upregulation of survivin in response to the treatment with IGF-1. In line with previous research, the downregulation of E-cadherin and the upregulation of N-cadherin, snail and vimentin induced by IGF-1 in HCC were positively associated with invasion and migration in a dose-dependent manner. On the basis of these findings, 
A

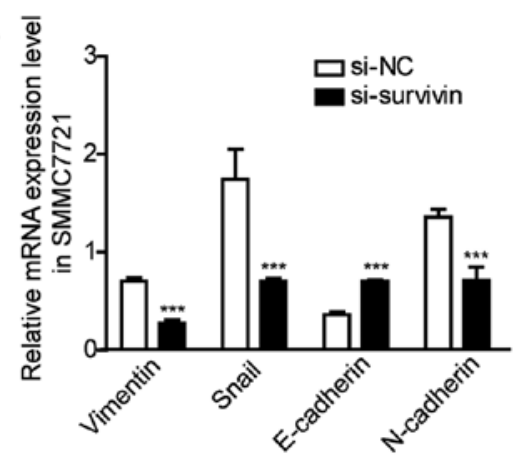

C

IGF-1

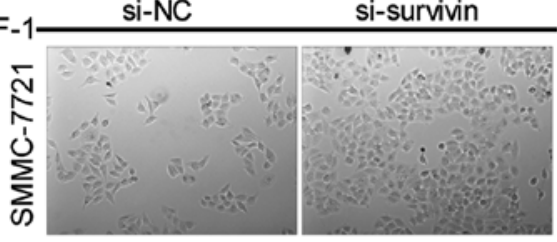

B

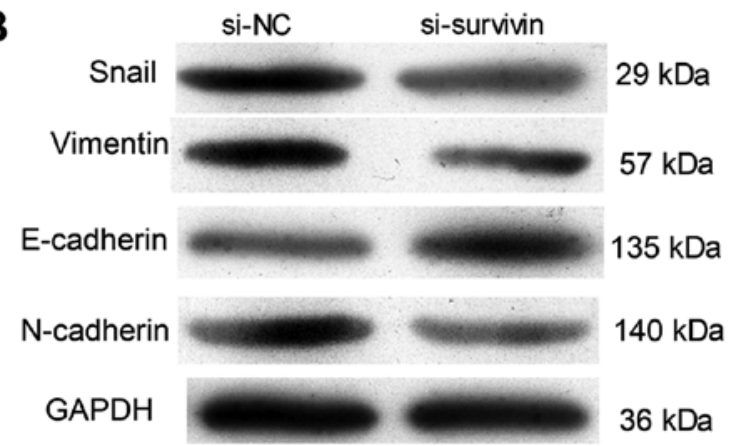

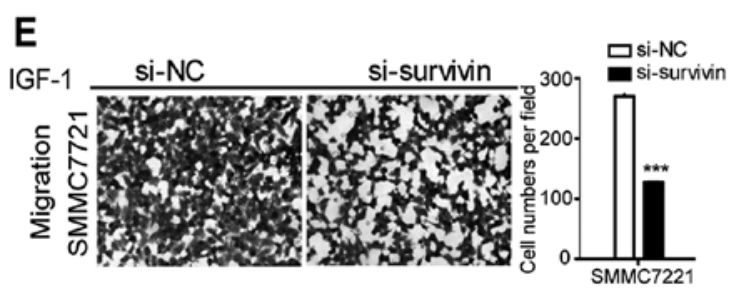

D
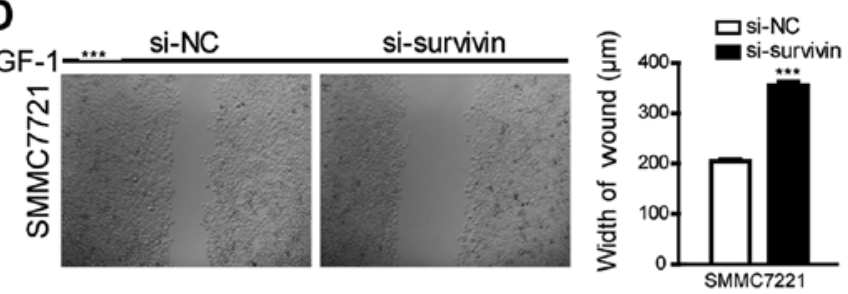

$F$
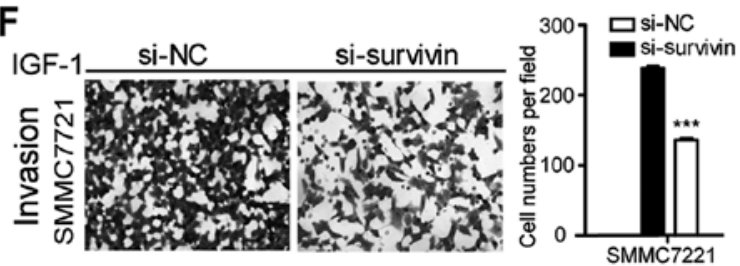

Figure 5. Knockdown of survivin inhibits the IGF-1-induced EMT process. (A) Relative mRNA expression of EMT-associated genes using RT-PCR after silencing of survivin and treatment with IGF-1. ${ }^{* *} \mathrm{P}<0.001$ compared to the control (B) Relative protein expression of EMT-associated genes using western blot analysis after silencing of survivin and treatment with IGF-1. (C) Cell morphological changes after silencing of survivin and treatment with IGF-1. (D) The impact of survivin on migration ability in a wound healing assay. ${ }^{* * *} \mathrm{P}<0.001$ compared to the control. (E) The impact of survivin on migratory ability in a Transwell filter assay. ${ }^{* * *} \mathrm{P}<0.001$ compared to the control. $(\mathrm{F})$ The impact of survivin on invasive ability in a Transwell filter assay. ${ }^{* * *} \mathrm{P}<0.001$ compared to the control. IGF-1, insulin-like growth factor-1; EMT, epithelial-mesenchymal transition.

our study suggests that IGF-1 may induce EMT involving E-cadherin, N-cadherin, Snail and vimentin dysregulation, thus facilitating the invasion and metastasis of HCC.

Survivin protein is overexpressed in most human tumors and promotes tumor cell proliferation and viability $(4,32)$. As a nodal protein, survivin interfaced with multiple signals involved in mitosis and apoptosis and functionally integrated proliferation, cell death and cellular homeostasis. Exploring strategies to lower the expression level of survivin has been viewed as effective cancer therapy. Usually, positive correlation between IGF and survivin can be observed in tumor cells. As a target of IGF-1, survivin protein translation can be driven by IGF-1 signaling in prostate cancer cells. Binding of IGF-1 to its receptor activates downstream kinases, mammalian target of rapamycin (mTOR) and p70S6 protein kinase (p70S6K), which modulates survivin mRNA translation to increase the apoptotic threshold (4). In the present study, we focused on the role IGF-1/survivin in metastasis of HCC, which has not been reported to date. However, target-therapeutic functions have been found in other cancers. Sato et al also indicated that IGF-1 can induce expression of survivin in renal cell carcinoma (32). Furthermore, we demonstrated that survivin depletion could recover the cohesive ability and epithelial phenotype of HCC cells lost with IGF-1 treatment. Collectively, these data confirmed that survivin participated in the IGF-1-mediating EMT process in HCC. To the best of our knowledge, this is the first study to elucidate the IGF-1/survivin cascade in HCC metastasis in vitro.
In conclusion, our results displayed indirect evidence that IGF-1 had an effect on metastasis of HCC by mediating the EMT process and activating survivin. AKT was also activated with the upregulation of survivin in response to treatment with IGF-1. These data provided a new insight for the molecular therapy of HCC patients in clinical treatment.

\section{Acknowledgements}

Not applicable.

\section{Funding}

The present study was supported by the Key Research and Development Plan in Shandong Province (2015GGH318017).

\section{Availability of data and materials}

The datasets used during the present study are available from the corresponding author upon reasonable request.

\section{Authors' contributions}

FL, YS, HZ, HG, XZ and HC conceived and designed the study. FL, YS, BL, JL and HL performed the experiments. FL, HZ and HC wrote the manuscript. HG and XZ reviewed and edited the manuscript. All authors read and approved the 
manuscript and agree to be accountable for all aspects of the research in ensuring that the accuracy or integrity of any part of the work are appropriately investigated and resolved.

\section{Ethics approval and consent to participate}

Not applicable.

\section{Patient consent for publication}

Not applicable.

\section{Competing interests}

The authors declare that they have no competing interests.

\section{References}

1. El-Serag HB: Hepatocellular carcinoma. N Engl J Med 365: 1118-1127, 2011.

2. Knox JJ, Cleary SP and Dawson LA: Localized and systemic approaches to treating hepatocellular carcinoma. J Clin Oncol 33: $1835-1844,2015$

3. van Zijl F, Zulehner G, Petz M, Schneller D, Kornauth C, Hau M, Machat G, Grubinger M, Huber H and Mikulits W: Epithelialmesenchymal transition in hepatocellular carcinoma. Future Oncol 5: 1169-1179, 2009.

4. Vaira V, Lee CW, Goel HL, Bosari S, Languino LR and Altieri DC: Regulation of survivin expression by IGF-1/mTOR signaling. Oncogene 26: 2678-2684, 2007.

5. De Craene B and Berx G: Regulatory networks defining EMT during cancer initiation and progression. Nat Rev Cancer 13: 97-110, 2013.

6. Haisa M: The type 1 insulin-like growth factor receptor signalling system and targeted tyrosine kinase inhibition in cancer. J Int Med Res 41: 253-264, 2013.

7. Liao G, Wang M, Ou Y and Zhao Y: IGF-1-induced epithelialmesenchymal transition in MCF-7 cells is mediated by MUC1. Cell Signal 26: 2131-2137, 2014.

8. Lei $\mathrm{T}$ and Ling $\mathrm{X}$ : IGF-1 promotes the growth and metastasis of hepatocellular carcinoma via the inhibition of proteasomemediated cathepsin B degradation. World J Gastroenterol 21: 10137-10149, 2015.

9. Su C: Survivin in survival of hepatocellular carcinoma. Cancer Lett 379: 184-190, 2016.

10. Yang P, Wang G, Huo H, Li Q, Zhao Y and Liu Y: SDF-1/CXCR4 signaling up-regulates survivin to regulate human sacral chondrosarcoma cell cycle and epithelial-mesenchymal transition via ERK and PI3K/AKT pathway. Med Oncol 32: 377, 2015.

11. Tai CJ, Chin-Sheng H, Kuo LJ, Wei PL, Lu HH, Chen HA, Liu TZ, Liu JJ, Liu DZ, Ho YS, et al: Survivin-mediated cancer cell migration through GRP78 and epithelial-mesenchymal transition (EMT) marker expression in Mahlavu cells. Ann Surg Oncol 19: 336-343, 2012.

12. Khan S, Aspe JR, Asumen MG, Almaguel F, Odumosu O, Acevedo-Martinez S, De Leon M, Langridge WH and Wall NR: Extracellular, cell-permeable survivin inhibits apoptosis while promoting proliferative and metastatic potential. Br J Cancer 100: 1073-1086, 2009.

13. Livak KJ and Schmittgen TD: Analysis of relative gene expression data using real-time quantitative PCR and the 2(-Delta Delta C(T)) method. Methods 25: 402-408, 2001.

14. Hollier BG, Evans K and Mani SA: Identication of optimal topography of the barotropic ocean model in the North Atlantic by variational data assimilation. Mol Cell Endocrinol 138: 41-50, 2009.
15. Onoue T, Uchida D, Begum NM, Tomizuka Y, Yoshida H and Sato M: Epithelial-mesenchymal transitions induced by the stromal cell-derived factor-1/CXCR4 system in oral squamous cell carcinoma cells. Int J Oncol 29: 1133-1138, 2006.

16. Fang YJ, Lu ZH, Wang GQ, Pan ZZ, Zhou ZW, Yun JP, Zhang MF and Wan DS: Elevated expressions of MMP7, TROP2, and survivin are associated with survival, disease recurrence, and liver metastasis of colon cancer. Int J Colorectal Dis 24: 875-884, 2009.

17. DeNardo BD, Holloway MP, Ji Q, Nguyen KT, Cheng Y, Valentine MB, Salomon A and Altura RA: Quantitative phosphoproteomic analysis identifies activation of the RET and IGF-1R/IR signaling pathways in neuroblastoma. PLoS One 8: e82513-e82513, 2013.

18. Chen J, Alberts I and Li X: Dysregulation of the IGF-I/PI3K/ $\mathrm{AKT} / \mathrm{mTOR}$ signaling pathway in autism spectrum disorders. Int J Dev Neurosci 35: 35-41, 2014.

19. Onder TT, Gupta PB, Mani SA, Yang J,Lander ES and Weinberg RA: Loss of E-cadherin promotes metastasis via multiple downstream transcriptional pathways. Cancer Res 68: 3645-3654, 2008.

20. Canel M, Serrels A, Frame MC and Brunton VG: E-cadherinintegrin crosstalk in cancer invasion and metastasis. J Cell Sci 126: 393-401, 2013.

21. Satelli A and Li S: Vimentin in cancer and its potential as a molecular target for cancer therapy. Cell Mol Life Sci 68: 3033-3046, 2011.

22. Ivaska J, Pallari HM, Nevo J and Eriksson JE: Novel functions of vimentin in cell adhesion, migration, and signaling. Exp Cell Res 313: 2050-2062, 2007.

23. Kudo-Saito C, Shirako H, Takeuchi T and Kawakami Y: Cancer metastasis is accelerated through immunosuppression during Snail-induced EMT of cancer cells. Cancer Cell 15: 195-206, 2009.

24. Zhou BP, Deng J, Xia W, Xu J, Li YM, Gunduz M and Hung MC: Dual regulation of Snail by GSK-3beta-mediated phosphorylation in control of epithelial-mesenchymal transition. Nat Cell Biol 6: 931-940, 2004.

25. Cosgrove BD, Mui KL, Driscoll TP, Caliari SR, Mehta KD, Assoian RK, Burdick JA and Mauck RL: N-cadherin adhesive interactions modulate matrix mechanosensing and fate commitment of mesenchymal stem cells. Nat Mater 15: 1297-1306, 2016.

26. Amsellem V, Dryden NH, Martinelli R, Gavins F, Almagro LO, Birdsey GM, Haskard DO, Mason JC, Turowski P and Randi AM: ICAM-2 regulates vascular permeability and N-cadherin localization through ezrin-radixin-moesin (ERM) proteins and Rac-1 signalling. Cell Commun Signal 12: 12, 2014.

27. Chen YS, Huang WL, Chang SH, Chang KW, Kao SY, Lo JF and Su PF: Enhanced filopodium formation and stem-like phenotypes in a novel metastatic head and neck cancer cell model. Oncol Rep 30: 2829-2837, 2013.

28. Sigurdsson V,Hilmarsdottir B, Sigmundsdottir H,Fridriksdottir AJ, Ringnér M, Villadsen R, Borg A, Agnarsson BA, Petersen OW, Magnusson MK, et al: Endothelial induced EMT in breast epithelial cells with stem cell properties. PLoS One 6: e23833, 2011.

29. Ma J, Sawai H, Matsuo Y, Ochi N, Yasuda A, Takahashi H, Wakasugi T, Funahashi H, Sato M and Takeyama H: IGF-1 mediates PTEN suppression and enhances cell invasion and proliferation via activation of the IGF-1/PI3K/Akt signaling pathway in pancreatic cancer cells. J Surg Res 160: 90-101, 2010.

30. Walsh LA and Damjanovski S: IGF-1 increases invasive potential of MCF-7 breast cancer cells and induces activation of latent TGF- $\beta 1$ resulting in epithelial to mesenchymal transition. Cell Commun Signal 9: 10, 2011.

31. Li C, Li J, Wu D and Han G: The involvement of survivin in insulin-like growth factor-1-induced epithelial-mesenchymal transition in gastric cancer. Tumour Biol 37: 1091-1096, 2016.

32. Sato A, Oya M, Ito K, Mizuno R, Horiguchi Y, Umezawa K, Hayakawa $M$ and Murai M: Survivin associates with cell proliferation in renal cancer cells: Regulation of survivin expression by insulin-like growth factor-1, interferon-gamma and a novel NF- $\kappa B$ inhibitor. Int J Oncol 28: 841-846, 2006. 